Обзорная статья/Review article

УДК 336

DOI: http://doi.org/10.20914/2310-1202-2017-1-326-331

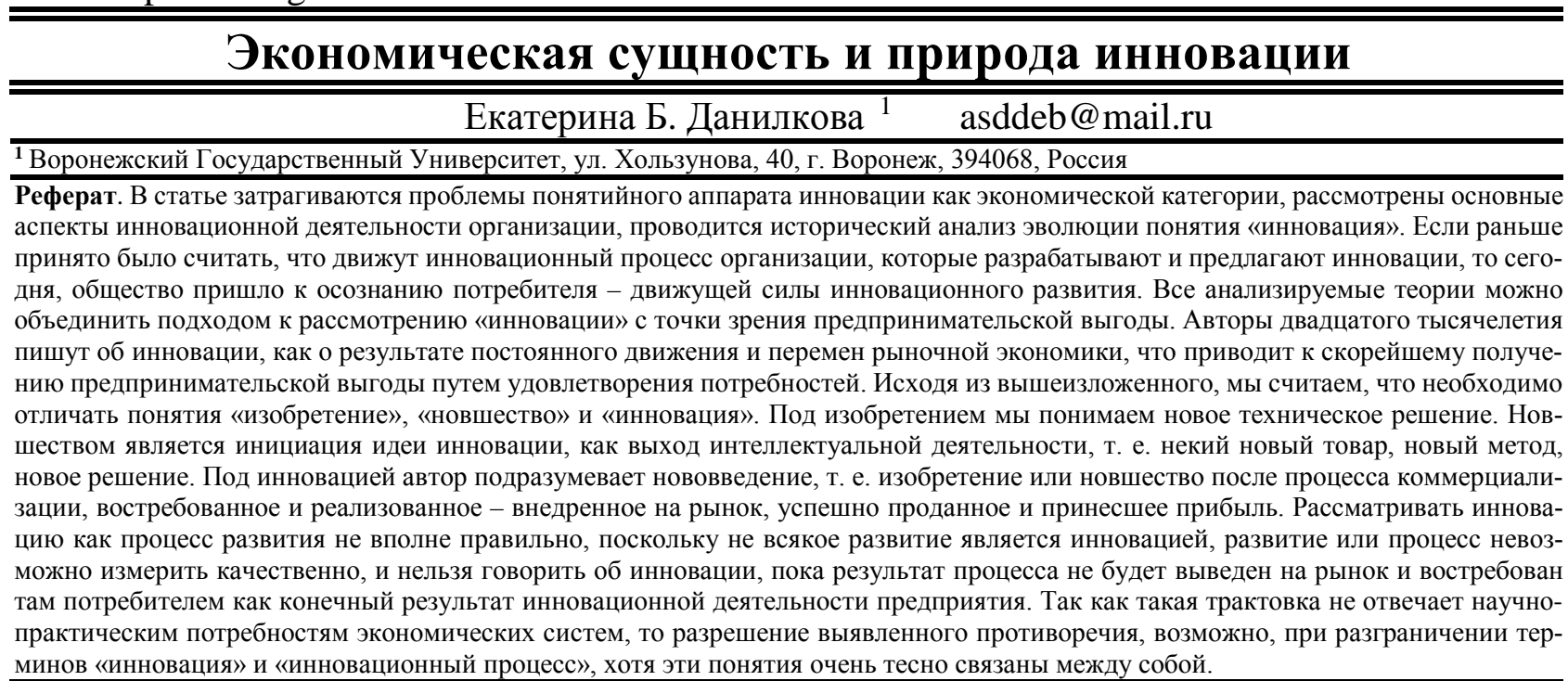

Ключевые слова: инновация, нововведение, новшество, инновационный процесс, управление инновациями, предприниматель, инновационность.

\title{
The economic essence and the nature of innovation
}

Ekaterina B. Danilkova 1 asddeb@mail.ru
Summary. The article addresses the problems of the conceptual apparatus of innovation as an economic category, the basic aspects of the
innovation activities of the organization, conducted a historical analysis of the evolution of the concept of "innovation”. Previously, it was
customary to assume that the process is driven by innovative organizations that develop and offer innovations, today; society has come to the
realization of the consumer - the driving force of innovation development. All the analyzed theory can be combined approach to “innovation"
consideration in terms of business benefits. The authors of the twentieth millennium write about innovation because of constant movement
and change of the market economy, which leads to the speedy preparation of pre - businessman benefits by satisfying needs. Based on the
foregoing, we believe that it is necessary to distinguish the concept of "invention” and "innovation”. Under the invention, we mean a new
technical solution. An innovation is the initiation of the idea of innovation as a way out of intellectual activity, i. e., a new product, a new
method, a new solution. By innovation author implies innovation, ie an invention or innovation after the commercialization process, demanded
and implemented - introduction to the market, has successfully sold and which brought a profit. Treat innovation as the development process
is not entirely correct, because not every development is innovation, development or process cannot be measured qualitatively, and it is im-
possible to talk about innovation as a result of the process will not be launched on the market and consumer demand there as the final result
of the innovative activity of the enterprise. Because such an interpretation does not meet the scientific and practical needs of economic systems,
the resolution of the identified contradictions, perhaps for the demarcation of the terms “innovation” and “innovation process", although these
concepts are very closely linked.
Keywords: innovation, novation, innovative process, management innovation, businessman, innovativeness.

\section{Введение}

Современный менеджмент в первую очередь представляет собой управление, основывающееся на нововведениях. Важнейшей составной частью менеджмента являются инновации, которые представляют собой процесс постоянного обновления во всех сферах деятельности.

Термин «инновация» очень широко используется в различных сферах экономики и менеджмента, поэтому, для уточнения понятия «инновация» необходимо рассмотреть взгляды различных авторов на сущность данного явления. Изучение подходов к определению сущности

Для цитирования

Данилкова Е. Б. Экономическая сущность и природа инновации // Вестник ВГУИТ. 2017. Т. 79. № 1. С. 326-331. doi:10.20914/23101202-2017-1-326-331

326 инновации и инновационной деятельности позволит нам выявить неоднозначность толкования термина с разных точек зрения. Рассуждая об инновациях и ускоренном формировании инновационной экономики, принято полагать, будто инновация - это детище настоящего времени. Однако на наш взгляд, это не так. Проанализируем историческую эволюцию подходов к изучению термина «инновация».

Определение «инновация» впервые появилось в научныХ исследованиях культурологов в XIX в. и означало тогда введение некоторых элементов одной системы в другую. Закономерности технологических нововведений стали изучаться только в начале XX века.

For citation

Danilkova E. B. The economic essence and the nature of innovation. Vestnik VGUIT [Proceedings of VSUET]. 2017. Vol. 79. no. 1. pp. 326-331. (in Russian). doi:10.20914/2310-1202-2017-1-326-331 
На наш взгляд, все анализируемые теории можно объединить подходом к рассмотрению «инновации» с точки зрения предпринимательской выгоды. Авторы двадцатого тысячелетия пишут об инновации, как о результате постоянного движения и перемен рыночной экономики, что приводит к скорейшему получению предпринимательской выгоды путем удовлетворения потребностей.

Значительный вклад в изучение инновационной деятельности внес Й.А. Шумпетер, обосновавший созидательную роль кредита, его «покупательную силу» в новаторской деятельности. Им же определено функциональное назначение инновационной сферы: коммерческий анализ потенциальных потребностей инноваций; поиск перспективных идей, источников функционирования; организация создания и внедрения новшества; тиражирование; поддержка и утилизация. В 1911 году в своей работе «Теория экономического развития» Шумпетер впервые выделил инновационность, как основную отличительную черту предпринимательства. В своей книге Й. Шумпетер трактует понятие «предприниматель» как «новатор». Он пишет: «...предпринимателями мы называем хозяйственных субъектов, функцией которых является как раз осуществление новых комбинаций и которые выступают как его активный элемент». Й. Шумпетер понимал под инновациями использование новых комбинаций существующих производительных сил для решения коммерческих задач и видел в них источник развития экономических систем. Переход из одного уровня качества на другой, процесс, когда производственная система переходит в иную плоскость с новыми, более качественными параметрами, также подразумевается им как некая инновация. По словам Й.А. Шумпетера, «радикальные» инновации определяют облик крупных перемен в мире, тогда как «инкрементальные» инновации наполняют собой процесс изменений непрерывно.

Согласно с Шумпетером А. Маршалл говорил об инновационном характере предпринимательства. Он был убежден, что предпринимательство всегда связано с инновациями, подразумевая нововведения и новшества. Однако следует заметить, что в отличие от Й.А. Шумпеттера, А. Маршалл никогда не отождествлял понятия предпринимателя и инноватора. Он утверждал, что действительная роль предпринимателей в жизни общества состоит в том, что они своими новшествами создают новый порядок, что влияет на процесс развития общества.

А. Маршалл выделяет несколько путей инновационного развития:

1. создание нового материального блага;

2. внедрение нового способа производства:

3. завоевание нового рынка сбыта;

4. использование нового вида сырья;

5. ведение новой организации дела.
Особое развитие инновационная деятельность получила в постиндустриальном обществе. Исследование Д. Белла в книге «Постиндустриальное общество» определяет инновационный характер новых социально-экономических условий развития предприятий с учетом повышения качества жизни населения в рыночных условиях. Он разделяет процесс производства на три сектора: сельское хозяйство, промышленность и сферу услуг. В третьем секторе доминирует спрос на наукоемкие технологии, информацию и знания, т. е. на информационные, интеллектуальные и организационные инновации.

К. Маркс в своих трудах отмечал, что важными элементами рынка является подготовленная рабочая сила с учетом ее знаний и способностей, что для организации даже более важно, чем капитал. К. Маркс рассматривал вопрос о капиталосберегающих инновациях как способе удешевления постоянного капитала, препятствующего падению нормы прибыли.

Так, ученые, проводившие исследования в области роста экономики, отмечают, что на протяжении всего развития человечества движущей силой его развития являются инновации.

Адам Смит в монографии «The Wealth of Nations», изданной в 1776 году, отмечал, что организационным механизмом капитализма служит не только рыночная система (соотношение спроса и предложения), но и конкуренция, которая заставляет непросто удовлетворять всевозрастающие потребности посредством понижения цен и улучшения качества, но и делать это наиболее эффективным способом, с помощью перехода на новые технологии, т. е. при помощи инноваций. Этот постулат со временем приобрел более емкое содержание и значение. Важным становится тот факт, что сегодня на свободных рынках фирмы используют инновации как наиболее действенный фактор в процессе борьбы за потребителя. А. Смит в своей работе показал воздействие организационной инновации на развитие как предприятий в частности, так и общества в целом. Он заметил, что богатство страны определяет развитость промышленности.

Д. Рикардо разделяет прогресс на два вида:

1. землесберегающие: нововведение и инновации

2. сберегающие: капитал и труд.

Следует отметить внимание к вопросу инноваций австрийца Ф. Хайека (1899-1992) и американца Б.М. Фридмена. Одним из центральных тезисов Ф. Хайека является положение о принципиальной ограниченности человеческого знания и невозможности его существования в концентрированной форме, в виде законченного набора сведений, воплощенных в формулах и цифрах. По его мнению, значительная часть знания имеет интуитивный характер. 
Р. Фостер также обращает внимание на инновации, которые создают новые конкурентные преимущества. По мнению Р. Фостера в битве за рынки между новаторами (атакующими) и обороняющимися (защищающими свои нынешние доходы) результат заранее предугадан победой новаторов.

М. Портер тоже пишет, что: «успех в конкуренции не есть достижение равновесия, а постоянное движение, перемены».

И среди отечественных ученых высок интерес к инновациям. Так в 20-е годы XX столетия Н.Д. Кондратьев разработал теорию длинных волн, в которой главную роль отводил научнотехнологическим инновациям. В каждой из волн, по его мнению, кардинально меняется структура хозяйства и все ее компоненты.

В общественном продукте происходит массовое появление новых товаров и услуг, в техническом базисе развиваются новые технологии, методы производства, источники сырья и энергии, изменяются формы организации, производства и управления, обучение и подготовка работников. Й.А. Шумпетер связал волнообразное развитие экономики по Кондратьеву с протеканием инновационных процессов.

Современная российская школа инноваций в единстве с теорией циклов и кризисов берет свое начало с 1988 г. когда в монографии Ю.В. Яковца «Ускорение научно-технического прогресса: теория и экономический механизм» была предложна классификация инноваций (технических нововведений) по уровню новизны. Там же введено понятие инновационного цикла, определена его структура, раскрыта связь с научными, изобретательскими и инновационными циклами, рассмотрен механизм освоения нововведений, охарактеризован дифференциальный научнотехнический доход (позднее он получил название технологической квазиренты) как главный стимул освоения изобретений.

Ближе к концу второго тысячелетия, многие отечественные авторы занялись вопросом изучения термина «инновация».

Исследуя понятие «инновация» с точек зрения различных авторов можно четко выделить ряд авторов, которые рассматривают термин как результат деятельности и других, которые считают инновацию неким процессом.

Проанализируем авторов, считающих инновацию конечным результатом, продуктом или услугой. К таковым относятся: Ю.П. Анисимов, С.Л. Брю, Л.М. Гохберг, К.Р. Макконнелл, Р.А. Фатхутдинов, Л.Д. Хацкевич, Э.А. Уткин и др $[1,2]$.

По мнению Э.А. Уткина и Г.И. Морозовой, инновация представляет собой объект, внедренный в производство в результате проведенного научного исследования или сделанного открытия, качественно отличный от предшествующего аналога.
Еще одно определение инновации дают Б.А. Райзберг и Л.Ш. Лозовский, определяя ее как нововведения в области техники, технологии, организации труда и управления, основанные на использовании достижений науки и передового опыта, а также использование этих новшеств в самых разных областях и сферах деятельности.

К.Р. Макконнелл и С.Л. Брю используют понятия инновация и нововведение как синонимы, подразумевая под ними запуск в производство нового продукта, внедрение нового производственного метода или применение новой формы организации бизнеса.

Напротив, Р.А. Фатхудинов считает, что необходимо разграничивать понятия «новшество» и «инновация». Новшество он определяет как оформленный результат фундаментальных, прикладных исследований, разработок или экспериментальных работ, а какой-либо сфере деятельности по повышению ее эффективности. Инновация - это конечный результат внедрения новшества с целью изменения объекта управления и получения экономического, социального, экологического, научно-технического и другого вида эффекта.

Сироткина Н.В. идентифицирует понятия «нововведение» и «инновация», подразумевая под данным термином прогрессивное новшество, задействованное в динамике, которое является новым для организационной системы, принимающей и использующей ее. Однако автор рассматривает инновацию и как процесс. Н.В. Сироткина пишет: «инновация - это комплексный процесс создания, распространения и использования новшеств для удовлетворения определенных потребностей» [6].

Исходя из вышеизложенного, мы считаем, что необходимо отличать понятия «изобретение», «новшество» и «инновация». Под изобретением мы понимаем новое техническое решение. Новшеством является идея инновации, как выход интеллектуальной деятельности, т. е. некий новый товар, новый метод, новое решение. Под инновацией автор подразумевает нововведение, т. е. изобретение или новшество после процесса коммерциализации, востребованное и реализованное - внедренное на рынок [2, 3].

Коллектив авторов в лице Л. Хацкевича, И. Шишкина, О. Макеевой, И. Паринова полагают, что инновацию можно определить как обеспечивающий конкурентные преимущества конечный результат творческой деятельности, получивший воплощение в виде нового или усовершенствованного продукта, внедренного на рынке, нового или усовершенствованного технологического процесса, используемого в практической деятельности, либо в новом подходе к социальным услугам. Под инновационным 
предпринимательством следует понимать процессы создания и продвижения конкурентоспособных продукции и услуг на основе технико-технологических, экономических, организационных, информационных и социальных нововведений.

Ю.П. Анисимов считает, что инновации представляют собой новую наукоемкую продукцию, товар или услугу, технологию, новые методы управления, востребованные рынком и защищенные как объекты интеллектуальной собственности, или являющиеся секретом мастерства (ноу-хау).

Инновация (нововведение, инновационный продукт) - результат инновационной деятельности, получивший воплощение в виде нового продукта, услуги и технологии и/или новой организационно-экономической формы, обладающий явными качественными преимуществами при использовании в проектировании, производстве, сбыте, потреблении и утилизации продуктов, обеспечивающий дополнительную по сравнению с предшествующим продуктом или организационно-экономической формой экономическую (экономия затрат или дополнительная прибыль) и/или общественную выгоду.

В популярной экономической энциклопедии под данной категорией понимаются нововведения, конечный результат инновационной деятельности, связанной с вложением средств в экономику и обеспечивающей смену поколений техники и технологий.

Однако существует и другой подход, при котором инновация рассматривается как процесс качественного изменения, введения новых изделий, техники и технологии, формирование новых отношений по их поводу. К таким авторам относятся: П. Дракер, Б. Твисс, Б. Санто, Л.С. Брютин, В.Я. Горфинкель, Н.В. Сироткина, П. Завлин и другие.

Б. Твисс определяет инновацию как процесс, в котором изобретение или идея приобретает экономическое содержание.

Б. Санто считает, что инновация - это такой общественный, технический и экономический процесс, который через практическое использование идей и изобретений приводит к созданию лучших по своим свойствам изделий, технологий, и в случае, если она ориентируется на экономическую выгоду, прибыль, появление инновации на рынке может привести добавочный доход.

Л.С. Брютин пишет: «инновация - управляемый процесс, имеющий комплексный характер и заключающийся во внедрении различных изменений в существующие системы и структуры с целью создания, распространения, использования принципиально нового или модифицированного практического средства, удовлетворяющего конкретные общественные потребности и дающего экономический, технический и социальный эффект».

П. Друкер рассматривает инновацию как средство, специфический инструмент предпринимателя, дающий возможность использовать изменения для открытия нового бизнеса.

В.Я. Горфинкель считает инновацией «...комплексный процесс создания, распространения и использования новшеств для удовлетворения человеческих потребностей, меняющихся под воздействием развития общества» [9].

Н.В. Сироткина под нововведениями понимает сложный комплекс различных видов деятельности, начиная с возникновения идеи и последующих стадий исследования, разработок, проектирования, изготовления нового образка, анализа рынка сбыта до поступления новой продукции в сферу сбыта. С чисто экономической точки зрения нововведение - это прибыльное использование научно-технических и других достижений посредством производства новой потребительской стоимости.

П. Завлин предлагает следующее определение: «Инновация - использование результатов научных исследований и разработок, направленных на совершенствование процесса деятельности производства, экономических, правовых и социальных отношений в области науки, культуры, образования и в других сферах деятельности общества».

Согласно классификации инноваций все существующие определения, по мнению Завлина, можно отнести в пяти основным подходам к их определению:

- объективному;

- процессному;

- объективно-утилитарному;

- процессно-утилитарному;

- процессно-финансовому.

Подход, представленный П.Н. Завлиным и А.Е. Варшавским, предполагает рассмотрение инновации как результата творческого процесса в виде создания новой техники, технологии, организационной структуры.

Д.А. Ендовицкий, С.Н. Коменденко под инновацией понимают качественное изменение видов, форм и методов хозяйственной деятельности, обусловленное внешними причинами и внутренними возможностями, направленное на повышение эффективности достижения целей организации.

Д.Ю. Трещевский использует продуктово-технологический подход, в соответствии с которым инновация - это новая либо усовершенствованная продукция или технология, обеспечивающая удовлетворение потребностей социально-экономической системы [8]. 
В. Юрьев, В. Смагина, Е. Смолина, О. Кацук [и др.] обобщили многие подходы к изучению понятия «инновация» и выделили ряд признаков, характеризующих и определяющих с разных сторон инновацию именно как экономическое явление [10].

Во-первых, инновация является результатом процесса целенаправленного качественного изменения объекта субъектом, обладающим элементами новизны.

Во-вторых, объектом инновационного изменения, изучаемым экономической теорией, является совокупность факторов производства и экономических отношений, возникающих по поводу их использования между участниками процесса производства.

В-третьих, активным деятельным субъектом инновационного процесса является человек, осуществляющий инновационную деятельность.

В-четвертых, инновации несут в себе полезные функции, заключающиеся в том, что они делают экономически возможным адаптацию товаров к индивидуальным потребностям конкретных групп потребителей, т. е. потребительских панелей [11-13].

И, наконец, в-пятых, инновация обладает эффективностью комплексного характера.

Такое большое количество определений термина «инновация» связано, на наш взгляд, не только со сложностью природы инноваций, но и также со спецификой, возникающей в зависимости от объекта и предмета исследования. Однако во всех исследуемых определениях существуют и общие характеристики инноваций. Под инновацией следует понимать только радикальные изменения, которые влияют на конечный результат деятельности. Из всех определений видно, что основная цель инновации заключается в изменении объекта управления и получение некоторого эффекта (экономического, технического или другого).

\section{ЛИТЕРАТУРА}

1 Анисимов Ю.П., Полукеева А.В. Системный подход к управлению инновационной деятельностью предприятия // Развитие предприятий машиностроения в России: проблемы, опыт, перспективы: Материалы Международной научно-практической конференции. 2015. С. 41-48.

2 Гохберг Л.М., Кузнецова И.А. Инновационная деятельность // Основы инновационного менеджмента: Учеб. пособие / Под ред. проф. В.В. Коссова. М.: Магистр. 2009. С. 37-74.

3 Данилкова Е.Б. Проблемы и перспективы перехода страны от сырьевой к инновационной экономической модели // Актуальные проблемы региональной экономики и территориального управления: сборник статей. Воронеж, 2013, Вып.15. С. 14-17

\section{Заключение}

По нашему мнению, инновационный процесс означает последующее чередование этапов жизненного цикла инновации, включает в себя процесс создания инновации, производства, апробации, распределения, обмена и потребления.

На современном этапе рыночной экономики высокий уровень конкуренции считается нормальным явлением, поэтому предприятие вынуждено посредством инноваций и инновационного процесса, находить и создавать оригинальные конкурентные преимущества своей продукции. Инновационные преобразования затрагивают все сферы деятельности предприятия и должны быть направлены в первую очередь на удовлетворение общественных потребностей. То есть, в настоящее время, без применения инноваций невозможно создать наукоемкую конкурентоспособную продукцию.

Заметим, что не все инновации столь необходимы предприятию. Инновационная деятельность подразумевает высокий уровень риска, а также большие финансовые затраты, поэтому, к вопросу внедрения инновации надо подходить сознательно, рассчитав заранее целесообразность и риски.

Технология формирования инновационной деятельности должна включать в себя этапы сбора и анализа необходимой информации, прогнозирование результатов инновационной деятельности, реализацию творческого потенциала трудового коллектива, наличие нормативной базы и отлаженных механизмов принятия решений.

В российской практике особенно важна стадия завершения инновационного процесса и выхода продукта (инновации) на рынок, потому что большое количество инновационных идей не доходят до стадии реализации в силу недостаточности инвестиций и по другим причинам.

4 Данилкова Е.Б. Методики оценки инновационного потенциала региона // Управление изменениями в социально-экономических системах: сборник статей 13 Международной научно-практической конференции. Воронеж, 2014. С. 168-174.

5 Яковец Ю.В. Охрана и эффективное использование научных открытий и изобретений - основа стратегии инновационного прорыва. М. : ИНЭС - МИСК, 2015. 104 с.

6 Сироткина Н.В., Чупрова И.Ю. Инновационная стратегия развития высокотехнологичных регионов. Новый взгляд с позиции формирования экономики знаний // Регион: системы, экономика, управление. 2016. № 3 (34). С. 36-42.

7 Стратегия инновационного развития Российской Федерации на период до 2030 года, [Электронный pecypc]. URL: http://www.consultant.ru (дата обращения: 06.12.2016). 
8 Трещевский Д.Ю. Управление инновационным развитием регионов: принципы, стратегии, инструментарий. Воронеж: ВГУ, 2013. 176 с.

9 Горфинкеля В.Я. Экономика предприятия. М.: ЮНИТИ-ДАНА, 2012. 767 с.

10 Юрьев В.М., Чекулина Т.А. Формирование концепции инновационного развития экономики с позиций практико-ориентированного подхода // Вестник Тамбовского университета. Серия: Гуманитарные науки, 2011. № 12-2. С. 421-427.

11 Ülgen F. Schumpeterian economic development and financial innovations: a conflicting evolution // Journal of Institutional Economics. - 2014. - T. 10. №. 02. - C. 257-277.

12 Galindo M. Á., Méndez M. T. Entrepreneurship, economic growth, and innovation: Are feedback effects at work? // Journal of Business Research. - 2014. - T. 67. - №. 5. - C. 825-829.

13 Snieska V., Valodkiene G. Impact of innovations upon economic growth during recession // Technological and Economic Development of Economy. 2015. - T. 21. - №. 4. - C. 626-642.

\section{REFERENCES}

1 Anisimov Yu. P. Polukeeva A.V. Системный подход к управлению инновационной деятельностью предприятия. Razvitie predpriyatij mashinostroeniya v Rossii problemy opyt perspektivy Materialy Mezhdunarodnoj nauchno-prakticheskoj konferencii. [The development of engineering enterprises in Russia: problems, experience and prospects: materials between people's scientific-practical conference.], 2015, pp. 41-48. (In Russian)

2 Gohberg L.M., Kuznecova I.A. Innovacionnaya deyatelnost [Innovative activities]. Moscow, M.: Master., 2009. pp.37-74. (In Russian)

3 Danilkova E.B. Problems and prospects of the country's transition from raw to innovative economic model. Aktual'nye problemy regional'noi ekonomiki i territorial'nogo upravleniya: sbornik statei [Actual problems of regional economy and terrial management: a collection of articles]. Voronezh. 2013. no.15. pp. 14-17

4 Danilkova E.B. Valuation techniques Innova-insulating capacity of the region. Upravlenie izmeneniyami $v$ sotsial'no-ekonomicheskikh sistemakh: sbornik statei 13 Mezhdunarodnoi nauchno-prakticheskoi konferentsii

\section{СВЕДЕНИЯ ОБ АВТОРАХ}

Екатерина Б. Данилкова преподаватель, кафедра экономики и управления организациями, Воронежский Государственный Университет, ул. Хользунова, 40, г. Воронеж, 394068, Россия, asddeb@mail.ru

\section{КРИТЕРИЙ АВТОРСТВА}

Екатерина Б. Данилкова написала рукопись, корректировала её до подачи в редакцию и несёт ответственность за плагиат

КОНФЛИКТ ИНТЕРЕСОВ

Авторы заявляют об отсутствии конфликта интересов.

ПОСТУПИЛА 27.01.2017

ПРИНЯТА В ПЕЧАТЬ 20.02.2017
[Management of changes in the socio-economic systems: a collection of articles 13 of the International scientific-practical conference]. Voronezh. 2014. pp. 168-174

5 Yakovec Yu. V. Ohrana i ehffektivnoe ispolzovanie nauchnyh otkrytij i izobretenij osnova strategii innovacionnogo proryva. [Store and effective use of scientific discoveries and inventions - the basis of innovative breakthrough strategy], 2015. 104 p. (In Russian)

6 Sirotkina N.V., Chuprova I. Yu. The innovative strategy of development of high-tech regions. A new look from the perspective of the formation of the knowledge economy. Region: sistemy, ehkonomika, upravlenie. [Region: system, economy, management]. 2016, no. 3 (34), pp. 36-42. (In Russian)

7 Russian Federation Innovative Development Strategy for the period up to 2030 [Electronic resource]. URL: http://www.consultant.ru (accessed at 12.06.2016). (In Russian)

8 Treshchevskij D. Yu. Upravlenie innovacionnym razvitiem regionov principy strategii instrumentarij. [Management of innovative development of regions: the principles, strategies and tools]. Voronezh: VSU, 2013. 176 p. (In Russian)

9 Gorfinkelya V. Ya. Ekonomika predpriyatiya. [Enterprise economy]. Moscow: UNITY-DANA, 2012. 767 p. (In Russian)

10 Yurev V.M., Chekulina T.A. Formation of the innovative concept of development of the economy from the standpoint of practice-oriented approach. Vestnik Tambovskogo universiteta Seriya Gumanitarnye nauki. [Vestnik Tambov University. Series: Humanities]. 2011, no. 12-2, pp. 421-427. (In Russian)

11 Ülgen F. Schumpeterian economic development and financial innovations: a conflicting evolution. Journal of Institutional Economics. 2014. vol. 10. no. 02. pp. 257-277.

12 Galindo M. Á., Méndez M. T. Entrepreneurship, economic growth, and innovation: Are feedback effects at work? Journal of Business Research. 2014. vol. 67. no. 5. pp. 825-829.

13 Snieska V., Valodkiene G. Impact of innovations upon economic growth during recession. Technological and Economic Development of Economy. 2015. vol. 21. no. 4. pp. 626-642.

\section{INFORMATION ABOUT AUTHORS}

Ekaterina B. Danilkova lecturer, Economics and management of organizations department, Voronezh State University, Kholzunova str., 40, Voronezh, 394068, Russia, asddeb@mail.ru

\section{CONTRIBUTION}

Ekaterina B. Danilkova wrote the manuscript, correct it before filing in editing and is responsible for plagiarism

\section{CONFLICT OF INTEREST}

The authors declare no conflict of interest.

RECEIVED 1.27.2017

ACCEPTED 2.20.2017 